\title{
Discourses of Educational Rights in Philosophy for Children: On the Theoretical and Practical Merits of Philosophical Education for Children
}

\author{
Aireen Grace Andal \\ Ural Federal University \\ aireengrace.andal@gmail.com
}

Received 21 February 2019; accepted 6 November 2019; published 10 January 2020

\begin{abstract}
This article aims to put into dialogue Philosophy for Children (P4C) and education rights. Whereas rights have robust conceptualizations and have been the topic of many scholarly discussions, scholarship on $\mathrm{P} 4 \mathrm{C}$ still has a lot to unpack for a more expansive understanding, especially when scaled up to the level of rights. This work asks whether or not the rhetoric of "rights" can be used to discuss if $\mathrm{P} 4 \mathrm{C}$ has a rightful place to be a mandatory part of school curriculum. Thus the article explores how $\mathrm{P} 4 \mathrm{C}$ is positioned between children education and rights discourses. The range of views on $\mathrm{P} 4 \mathrm{C}$ is broad enough to prevent the concentration of discursive power in a single source or authority in terms of scale of discussion. $\mathrm{P} 4 \mathrm{C}$ is therefore subject to both scrutiny and praise in the same way that other human rights ideologies have been. In conclusion, this work hopes to speak and contribute to the literature on $\mathrm{P} 4 \mathrm{C}$ by problematizing children's discursive positions as learners and citizens with rights.
\end{abstract}

Keywords: Philosophy for Children; Childhood; Philosophy Education; Rights; Pedagogy

\section{Introduction: Debates on Philosophy for Children}

Founded by Matthew Lipman (2003), together with Ann Margaret Sharp, Philosophy for Children (P4C) promotes critical and creative habits developing the mind or facilitating meaning through philosophical discussions among students in primary and secondary schools and, less commonly, in extra-curricular contexts. Educators are likewise expected to facilitate thinking among groups of children as they deal with philosophical problems and arrive at reasonable judgments by virtue of thoughtful dialogue and critical reflections, building what is known as the community of inquiry. Instead of merely introducing the philosophical canon, the educators promote semi-structured dialogues or "collaborative inquiry", thus allowing children to grasp philosophical problems given their (yet) limited experience (Sowey, 2012). Haynes and 
Murris (2012) note that P4C offers a physical and metaphorical avenue to listen, speak, or remain observant, thereby enabling children to see for themselves the consequences of their decisions and actions, however simple or complex. P4C is interested in training young citizens to exercise their faculties of reason as evident in many of the initiatives which support the development of philosophy in schools.

This work argues that discussions on $\mathrm{P} 4 \mathrm{C}$ can be made richer when put in the context of discourses on childhood and rights; thus, it explores the interrelationship between the diverse set of childhood education discourses on the one hand and discourses on rights on the other to then reflect on the ways both discourses can sharpen our understanding of Philosophy for Children (P4C). Two major questions are at hand: (1) how is P4C situated between childhood and rights discourses? and (2) how can the discourses of childhood and rights help us better understand P4C? Any attempt to take on this task is by no means simple or conclusive. The goal is to set the scene for the questions that will generate further investigations by locating these concerns within philosophy of education research. The paper aims to spark reflection and further dialogue among scholars of philosophy of education about the ways in which the standards of P4C should be judged in different contexts.

\subsection{On Advocates and Critics}

While P4C enjoys much support, it also has its inevitable critics. Much of the scrutiny into $\mathrm{P} 4 \mathrm{C}$ is undertaken to uncover structures and agencies of power, lay bare the political forces to determine how the discourse of $\mathrm{P} 4 \mathrm{C}$ is biased, expose potential ideological and structural constraints and identify the sources that may disempower some discourses and privilege others (see Hand and Winstanley, 2008; Suissa, 2008). Recent theoretical and empirical research on these critiques still finds resonance in the context of liberal education. For instance, critics argue that while $\mathrm{P} 4 \mathrm{C}$ has the unique capacity to challenge many taken-for-granted issues related to school education and scale up discussions on pedagogy, it may also create and perpetuate hierarchies in the discourse of pedagogical approaches (Hand and Winstanley, 2008; Suissa, 2008). P4C has also been accused of promoting a curriculum that reflects liberalism's whitewashed 'neutrality' (Mills, 1997, p. 121) as well as limiting any constructive discussion and critique of social relations and systems of domination above and beyond the institution of education. P4C therefore legitimizes existing structures of power instead of serving as a mechanism for social transformation. For instance, $\mathrm{P} 4 \mathrm{C}$ 's approach to abstract reasoning skills has been argued to show partiality towards Western liberal democratic thinking, suggesting a deficiency in historical sensitivity and institutional awareness which calls into question the triumph of academic and techno-scientific rationality due to its part in exacerbating intellectual superiority of the West (Rivage-Seul, 1987). Storme and Vlieghe (2011, p. 13) even emphasize that "Philosophy for/with children is therefore rendered subservient to the existing [Western] regime". Meanwhile, Kohan (1995) also criticized P4C for its political neutrality, asserting that "if we don't question the foundations of a capitalistic society, we in fact accept these foundations and ... contribute to the uncritical acceptance of the status quo" (Kohan, 1995, p. 28). In the same vein, Rainville (2000, p. 67) expressed apprehension that the "purportedly neutral approach to philosophical inquiry does not necessarily lead to less marginalization of 
indigenous communities may unwittingly contribute to the marginalization of Indigenous peoples both in North America and around the world". P4C's liberal foundations embodied individualism that, through laws, fostered spaces for groups to have private property and rights, stressing that individuals are equal only within the rules of law and ignoring various arrangements people make outside state institutions. The image of the state itself as a "subject of liberation" is a belief that reifies hierarchy of identities and divides socially constructed groups (Bonefield, 2014, p. 127). Finally, the feminist Marie-France Daniel (1994) criticises P4C's curriculum as a male-dominated arena, which is especially visible in Lipman's P4C novels.

Yet, advocates of $\mathrm{P} 4 \mathrm{C}$ argue that this type of philosophy education is able to challenge the ideologies of whiteness and "othering" which have consolidated systems of thinking, acting and legislating on the basis of epistemic superiority (see Haynes, 2008; Murris and Haynes, 2012; Chetty, 2014; Burgh and Thornton, 2018). P4C has also succeeded in criticizing the privileged role of "expert" educators in setting the terms for education and speaking on behalf of less articulate children and other educators not involved in P4C (see Lipman and Sharp, 2003). Any universalistic focus on one kind of philosophy is therefore challenged with P4C offering a counter-narrative to a "sanitized, whitewashed, and amnesiac account of European imperialism and settlement" (Mills, 1997, p. 121) which ignores non-European/non-white individuals. P4C is also geared towards addressing Rainville's (2000, p. 67) concern that expects $\mathrm{P} 4 \mathrm{C}$ to "to incorporate historical detail and socio-cultural awareness into any programs which are meant to be truly liberatory". For example, at Buranda State School, in Brisbane, Australia, the philosophy program not only improved students' problem-solving skills but was also able to educate children regarding playground violence and bullying (UNESCO, 2009). Thus, P4C may harbour an epistemic inclusivity as it challenges the hierarchized, reifying social relations that maintain the myth of European superiority in the curriculum.

To this end, both advocates and critics of $\mathrm{P} 4 \mathrm{C}$ meet on a common ground. Each side argues that closer examination of $\mathrm{P} 4 \mathrm{C}$ in different contexts would be instructive since pedagogy is useless unless its practice is informed by relevant contextual details (Rivage-Seal, 1987). In this context, as has been seen, the validity of pros and cons is at best mixed. Hence, while there is a general consensus that educational institutions are to assist children in perceiving the world around them independently, the way this goal is achieved is at the crux of $\mathrm{P} 4 \mathrm{C}$ discussions. There are various systems and techniques of teaching philosophy, allowing the tone of public discourse on education to develop from a simple pro- vs anti-P4C approach to one that unpacks how philosophy education relates children's abilities, for whom it is intended and what problems it intends to solve. Indeed, there is reasonable evidence to suggest that the debates on $\mathrm{P} 4 \mathrm{C}$ involve a wide range of contesting discourses. It is then important not only to look at what P4C campaigns for as ideals, but also to consider its history together with the resulting pragmatic implications and ideological legacy (Ndofirepi, 2011).

\section{On Rights}

Much of the discussion on $\mathrm{P} 4 \mathrm{C}$ has searched for a democratic approach to doing philosophy by institutionalizing communities of thinkers (i.e. public sphere) to provide an opportunity for free and equal expression. Hence, it is worthwhile to examine the discourses around $\mathrm{P} 4 \mathrm{C}$ in 
terms of rights. In this 'age of rights' (see Finkel and Moghaddam, 2005), debates focus on whether the concept of rights should be applied only to some universal, shared, normative schemes such as life and liberty. Yet, when it comes to the other aspects of humanity (e.g. different culture), the concept is hardly a given. Scholars argue though that an important consideration that vindicates an academic responsibility towards introducing education as a right has to do with what human beings are entitled to, education being seen as an intermediary to maximize fundamental human rights. The debate on including education as a basic human right is fundamentally related to justice as it is about having equal access to what one ought to have. It is argued that an approach that is not based on the understanding of the concepts of justice and rights is self-defeating because rights cannot be asserted without knowing why individuals have entitlements and what these entitlements are. This entails the imperative to view education as a right. Yet rights may not be the only reason to justify education, let alone P4C. Observers of rights argue that experiences of human rights are not universal as these need "local translation and cultural imprint to be enacted by citizens" (Lyon, 2013, p. 179). Rights, in this sense, might not be the best argument for education. Rather, they only provide the context that defines how education is to be delivered and implemented.

\subsection{Debates on Children Education as a Right}

The rights of children as defined in existing national legislation almost always include education rights (see Kehily, 2004). It is not surprising then that the discourse of rights tends to amplify children's education to assert their political status, overemphasize formal, legal interpretations of political participation, and obscure the crucial need for recognition in authorizing children's public participation. Universally understood as a right, education starts to assume its relevance and influence - principally in terms of social growth and development amongst both children and adults. However, the concept of rights goes beyond the legal framework, touching upon the wider issues of human dignity (Polonko and Lombardo, 2005). In this regard, $\mathrm{P} 4 \mathrm{C}$ faces the question not only of providing philosophy education but also of how philosophical inquiry can impact children's lives, especially their perception of themselves as thinkers and participants in the broader world given their fractional experience at school. At the heart of these questions is the search for praxis. This implies upholding the practice of having an "appreciation for children's philosophical insights and unique perspectives, involving pedagogical and interpersonal strategies that manifest a commitment to making space for all children's voices" (Mohr Lone and Burroughs, 2016, p. 209). This poses a challenge to $\mathrm{P} 4 \mathrm{C}$ because, while it can be a potentially helpful tool in the development of children's capacity to think critically, it may not necessarily translate into children's democratic involvement since $\mathrm{P} 4 \mathrm{C}$ as an education right does not guarantee participatory engagement of children as citizens. Kizel (2019) even notes that the danger here is that children who do not come from hegemonic groups can experience two types of oppression. The first is 'external' where the thinking of children engaged in philosophical inquiry is dictated by the bigger hegemonic discourse in the dominant philosophical community. The second is 'internal' whereby children internalize the 'right order' and blindly follow the established power relations (p. 147). After all, educating children does not necessarily lead to educating future adults, which casts doubt on the way their rights as adults are addressed as well. Ultimately, the 'right to education' 
argument puts a lot of responsibility on institutions to enforce those rights. This usually includes the responsibility to judge and monitor how the right to education is enforced.

With all these concerns about $\mathrm{P} 4 \mathrm{C}$, what matters in the discussion about the demand for education in the context of rights is the role of philosophy teachers. Ideally, philosophy education assists citizens. If today's philosophy teachers assume this responsibility, then they face the challenge of understanding the dynamics of building a community of philosophical inquiry designed specifically for children. This raises the following question: how to educate children on such complex issues as cultural diversity, national heritage and freedom of self-determination, among others? The next question is about the extent to which $\mathrm{P} 4 \mathrm{C}$ can be understood as developing children's dignity outside education rights. Regardless of whether it is a matter of rights to participation, cultural diversity or mental health, there is an incentive to diversify ways of seeing P4C and its current status in the public space. Indeed, professional philosophy is one thing, but philosophy for non-philosophy students quite another, especially when the students are children (and members of the general public). Thus, today's philosophy educators are confronted with perpetual pragmatic and epistemic changes, especially when they teach philosophy for reasons related to human rights and dignity. They also need to understand the value of developing an attitude of wonder and speculation about the world which is hopefully one of enthusiasm and not despair. Understood broadly, a different configuration of criticism serves the purpose of one of the many goals of philosophy - to teach and train minds in the exploration of centuries of teachings and uncharted regions of our thought and experience. The current generation of philosophy teachers must therefore continue on this path and remain the primary alchemists in the stimulation of thinking.

\subsection{Beyond the Hierarchical Gaze: The Kind of Rights for P4C}

Thinking about $\mathrm{P} 4 \mathrm{C}$ in terms of human dignity challenges the limitations of conventional views on children education and rights. Dignity refers to the inherent entitlement of every person to hold other persons or institutions accountable (Darwall, 2004). Children's encounter with education, public policy and human rights is not only inherently valuable for their sense of well-being, but also central to how they function as political and public individuals. This validates children's status as complex social agents beyond the 'socialization theory', in which children are "symbolic embodiments of culture" rather than socially significant persons (James, 1993, p. 76) and "childhood" is important only in relation to future adulthood or "our future" (Qvortrup, 2004, p. 270). When children are actively engaged in philosophy, they are able to practice their own rights themselves. Nishiyama (2017) claims that children are democratic agents and must be included in deliberation-making as a measure of the democratic credentials of a society. Beyond mere "consultation exercises", philosophy for children is an approach that fosters deliberation and engagement with thoughts and issues that are crucial for the advancement of human rights (Cassidy, 2017, p. 320). Through deliberation, it is possible, even desirable, to engage children in decision-making through the confrontation of their perspectives as stakeholders. They will be able to expand their thinking and hone their logical and interdisciplinary skills so that they may grow, not stagnate. Indeed, several authors were also able to see children's potential as deliberators, recognizing them as active members of their communities and societies (e.g. Cassidy 2017; Nishiyama, 2017; Kjørholt, 2007; Cohen, 
2005). These studies involved children in the research process and have seen them as participants or social actors with political agency.

Leaving aside the binary debate of whether or not $\mathrm{P} 4 \mathrm{C}$ is hegemonic is not an easy matter but it does nuance the normative conceptualisation of human dignity and inclusiveness. While the focus on 'othering' can help criticise hegemonic practices related to teaching content and methods applied by educational institutions, it emphasizes a single vision of marginalization. The diversity of social relations expressing multiple particularities of history, experience and knowledge may be overlooked. Therefore, it is relevant to give sufficient attention to the mediated character of $\mathrm{P} 4 \mathrm{C}$ and theorise inclusiveness in the context of what admittedly is an imperfect pedagogical style. This might result in simplifying human diversity into antagonistic forces. Indeed, empirical studies show that various applications of Philosophy for Children lead to different outcomes in non-Western settings. For instance, Letseka (2014) calls for promoting a P4C that focuses on indigenous animals and nature in Africa because these have heuristic value that may better aid children in their learning of philosophical literacy. However, in the same 'othered' settings, there are examples of P4C's inclusive character expanded onto various cultures (UNESCO, 2009). For instance, the Malaysian experience is different so that it was easy to adapt and translate Lipman's original texts to Malaysian language (p. 26). While $\mathrm{P} 4 \mathrm{C}$ has the tendency to privilege certain views, reducing it into antagonistic binaries may result in a failure to recognize the diversity of $\mathrm{P} 4 \mathrm{C}$ implementation within the Western world itself. Various examples of reflective criticism surface in the West, examples that are invoked to challenge the original $\mathrm{P} 4 \mathrm{C}$ pedagogy, confronting the unbridled exercises of $\mathrm{P} 4 \mathrm{C}$ such as taken-for-granted values of punctuality and hard work (Cassidy, 2017) as well as demanding new ways of learning and methodological progress.

The issue is therefore not so much about the superiority of the West than it is about the various paths $\mathrm{P} 4 \mathrm{C}$ has trod. Even advocates of $\mathrm{P} 4 \mathrm{C}$ have been critical of its materials, which enabled them to envision alternative mechanisms that can create a more inclusive pedagogical system among geographically and symbolically distant groups and establish communicative relationships among children who might otherwise be strangers. Leaving the binary approach to the critical analysis of $\mathrm{P} 4 \mathrm{C}$ can facilitate the process of recognition by sparking controversy and giving voice to those that have been invisible by virtue of geographic distance and cultural inequalities. While $\mathrm{P} 4 \mathrm{C}$ cannot redistribute the economic capital necessary for children to access equality in education, it can potentially accord visibility to the vulnerable others. Thanks to $\mathrm{P} 4 \mathrm{C}$ issues are noticed and considered. This addresses substantive rather than tokenistic education. By seeing the problems of marginalized groups "felt" in various settings through critical assessments in education, stakeholders imagine the experiences of both near and distant others, considering their plight as worthy of reflection and engagement in education. This helps give political recognition to issues present in education by somehow including these concerns in the group of those entitled to recognition beyond the superior-inferior framework. For others, this is a necessary demonstration of education's substantive responsibility to vulnerable others - the non-reciprocal responsibility between those who have power and those who have none regardless of setting. 


\section{On Childhood}

With the advent of modernity, the concept of childhood developed significantly ${ }^{1}$ and children came to be seen as vulnerable members of the society who need care and guidance. Children became more public with the emergence of the schooling system that separated them from adults; that is, children go to school while adults work (Aries, 1962). Late Renaissance very much improved children care, starting the trend of setting up institutions where children can learn safely. Introducing Philosophy for Children provides philosophers with ample material for pedagogical investigation.

\subsection{Protection vs Exposure debates}

Notwithstanding the role of children in democratic processes in the society, there remains the question of their political capacity to practice full citizenship, for instance of being "not capable of elaborating or reflecting on moral principles" (Christiano, 2001 as cited in Nishiyama, 2017). Instead, being at the fringes of decision-making in the adult-centred politics is seen as only "reasonable" (O'Toole, 2003, p. 72). Children are still considered as downright vulnerable even though they enjoy much political agency nowadays thanks to advocates of their statutory institutional rights and roles as vulnerable members of the society (Kjørholt, 2007). Indeed, engaging children in social issues through education is criticized as a form of politicizing children too early. Politicizing children, that is, building and maintaining their genuinely political identity, is a normative requirement of justice and a central element of genuine democracy. Specifically, the difficulty to think of P4C as a right is linked to the question of whether philosophy is appropriate for children. Philosophy taught in universities is different from P4C. Philosophy demands various skills, which does not necessarily apply to children and teaching them philosophy. This questions the necessity of viewing P4C as an educational right. While children offer a unique social perspective to be included in public deliberation, critics are wary of demanding so much of them. The pitting of the legacy of philosophy against unknown but certainly different future(s) seems to be an insoluble problem and one needs to boil it down to some specific formulation(s). The demanding and highly technical task of philosophy that requires the critical reflection on conceptual developments, modes of thought and theoretical systems may have very little to do with poetically engaging children in both wonder and speculations about the world.

Yet critics consider P4C a venue of universalizing ideals, which may yield some subtle discriminatory aspects, hiding its authoritarian education behind a value-free façade (Baker et al., 2012). As subjects of philosophical education, children were necessarily essentialized by P4C. For instance, the understanding of childhood operates within the discourse of vulnerability and care. Indeed, for some scholars (see Dewey, 1966), children are special people who deserve

\footnotetext{
${ }^{1}$ While there is an ongoing debate on which age category should be considered as childhood, and so far there have been many initiatives to define and redefine this term (Allison and Alan, 2010), this work primarily focuses on those children who are in the period of compulsory education (e.g. aged 6-7 to 15-18) intended to distinguish children from infants.
} 
compassion in the social system. Researchers influenced by this tradition, therefore, focus on the ways in which children must be taught certain things and be refrained from others. An essentialist take on child identity may lead to the emergence of systems of colonial epistemic hegemony, where the values of 'worth' and 'humanity' of children can be unevenly distributed according to the interest of Western liberal standards. This reduces children to a subhuman category, the practice being narrated as justified normality. One example of that is Lipman's $\mathrm{P} 4 \mathrm{C}$ emphasis on the traditions of the teacher's pedagogical authority, which "refuses the symmetrical pattern of pedagogical action" (Juuso, 2007, p. 77).

The literature is heavy with arguments that children are "neither seen nor heard" insofar as their relationship with democracy is concerned (e.g. Cohen, 2005) precisely because children are imagined to be extremely unqualified to engage in social and political life, while learning can sometimes become limited and tunnelled, which ultimately inhibits its maximisation. However, the assumption that children are 'too young' to understand philosophy can be misleading. That children are unprepared to participate in political life is due to oversimplification of their ability to explore and respond to political problems. Scholars claim that using age as the only indicator of one's capacity to engage in "mature" topics might be flawed because age alone does not determine one's capacity for assessing the world. The capacities of children are frequently underrated and those of adults overrated. This critical reassessment of the ability of children to act as autonomous and self-determining agents opened the door to a larger societal discussion of the rights and roles of children. For instance, children become special people who attract interests of particular agents - states, lobbyists, charity organizations - thanks in part to the liberal public attention and sympathy mobilized by powerful images and discourses that construct childhood.

\subsection{Beyond an Essentialist-Non-Essentialist Gaze}

The status of children as learners provides an opportunity to examine the 'exception' in order to better understand 'the rule' as exceptional circumstances tend to expose the social structures and processes that are often hidden in the ordinariness of everyday life. While concerning itself with the future of philosophy as an academic discipline, Philosophy for Children has generally assumed some understanding about children. Ultimately, key critical concerns suggest that the way children are understood be extended. For instance, workshops for philosophy teachers encourage the inclusion of deliberative teaching methodologies that prompt students themselves to discuss issues that affect local communities, such as health, environment and bioethical issues. These are addressed and evaluated by students and their teachers (UNSECO, 2009). Storme and Vlieghe write that (2012, p. 26), "it is exactly this experience of childhood as a suspension of the logic of bare life that can be shared amongst the participants of philosophy for/with children, making of every participant a neotenic infant". Indeed, the most evident attempts to articulate a definition of children in P4C endorse loosely the desirability of dialogue negotiating the identity of children. These sentiments are not inherently problematic, but they can appear limited to the point of banal in determining what counts as Philosophy for 'Children'. This necessitates a more nuanced and contextual understanding of children as they enter a range of social, historical and political contexts of philosophical traditions. 
Moreover, the problem may not be so much about the curriculum as it is about the educators, or, more precisely, their marginalisation. A more diverse group of philosophy educators is needed not just for equal representation, but for more points of reference so that students can be exposed to differences. There are, of course, structural challenges such as funding and job security issues, as well as social challenges such as student interests. Geographic issues are also intertwined with how the future state of philosophy can be imagined. For instance, the shrinking employment all over Europe and strengthening of BRICS economies may contribute to opting for jobs offering immediate employment. Devoting time to teaching philosophy without a guarantee of tenure increases the chances of choosing philosophy as a major, which may affect the future ratio of $\mathrm{P} 4 \mathrm{C}$ teachers and students.

Another agenda to pay attention to is that of providing a method for engaging children in the investigation of central questions concerning rights and values. Beliefs can indicate, directly or indirectly, how students decide and make choices (Kuhn, 2001, p. 1) where a learner's epistemological position "influence the ways in which they are disposed to use their intellectual skills". In the late 20th century, belief systems are incorporated into research agendas in the field of education. Personal beliefs and value systems are considered as key elements that impact student learning and behaviour (see Nespor, 1987). What is important here are not only student beliefs but also those of the teacher. For example, beliefs are the basis of compatibility between teacher and student and thus affect both the learning and teaching processes (Meehan, 2007). Teachers are also "meaning-makers" drawing on the knowledge and skills they have acquired in their lifetime (Erricker et. al., 1997). Their beliefs about the nature of the learners will affect their way of teaching.

\section{P4C and Beyond: What Transpires amidst the P4C Debates?}

P4C may offer an opportunity to oppose the "civilising force of hypocrisy" (Elster 1998: 12). This performative element of $\mathrm{P} 4 \mathrm{C}$ is important in fostering political relations between the nation and children. The debates on $\mathrm{P} 4 \mathrm{C}$ encourage reflexivity by forming new ways of thinking about children, education and rights, which may not have been formed without the debates. It is a movement that gives voice to unarticulated views. The debates render certain concerns visible, thereby pressing $\mathrm{P} 4 \mathrm{C}$ into public deliberation. The differences among perspectives and discourses indicate vibrant public spaces. Both justifications and critiques took various directions to deal with different perspectives and motivations for subscribing to a particular discourse. The range of views is also broad enough to prevent the concentration of discursive power in a single source. This vibrancy, however, can be fleeting if a dominant discourse imposes a certain way of thinking, engaging and disengaging when it comes to in determining specific ways that Philosophy for Children is understood.

With Philosophy for Children as a negotiated subject, what does academic philosophy have to offer to provide a more nuanced, contextualised and rich understanding of teaching philosophy to children? Does it have to make visible the hegemonic tendencies of liberalism (i.e. colonialism and contemporary neoliberalism and neocolonialism)? This is also in line with inquiring whether or not philosophy scholars join the group of liberal parachute journalists, humanitar- 
ian workers, child welfare specialists, and child-centred project consultants. Indeed, the spectre of the colonial character of liberalism haunts the teaching of Philosophy for Children. As Derrida (1994, p. 11) reminds us, "a spectre is always a revenant" and there can be little control over its appearance. Educators of philosophy for children are therefore faced with the challenge of responding to liberalism's repetition and reproduction of the ideology of whiteness and 'othering' that might surface in one way or another.

\subsection{Speculations and Stint}

Various discussions on P4C offer an opportunity to view it in the context of a wider spectacle of the delicate global discussions about the right to education. The differing $\mathrm{P} 4 \mathrm{C}$ discourses welcome the emerging contestation in the age of rights and seek to examine alternative visions various global actors put forward. This can potentially broaden the discourse of education rights that speaks to different cultures and contexts. By being criticized, $\mathrm{P} 4 \mathrm{C}$ can be seen away from a universally rational order based on neutrality. Rather, it is an unsettled construct that must be defended using a contingent set of concepts and strategies. The language of children's rights is an example of these contested concepts. These are socially constructed, in the sense that the ideas and practices associated with them are created, re-created, and realized by various agents and institutions in specific social conditions. While P4C's universality is often invoked in international forums and popular press, its contingent character is manifest in how it is practiced, and the meanings associated with how it is experienced.

What transpires is that the intrinsic value of $\mathrm{P} 4 \mathrm{C}$ is not self-explanatory. $\mathrm{P} 4 \mathrm{C}$, while remaining a powerful point of reference for many, has been confronted with rival normative interpretations of what counts as a good pedagogy. As such, the constructivist view of children, childhood and child education suggests that universal values are differently experienced. And because human rights are not self-explanatory, they must be legitimized, justified, and subjected to the scrutiny of public deliberation. This is even more the case today when there are rival ideas.

\subsection{Switches and Shifts}

Surfacing normative standards by which contestations on children's rights take place necessitates a shift in our perspectives on educational norms. Rightful educational practices is a moving target that cannot be reached by focusing on normative impositions. P4C discourses suggest that there is no single deployment of a moral trump card. While invoking specific systems of pedagogy becomes necessary to respond to pragmatic deprivations (such as corporal punishments), these pedagogical systems are still under scrutiny. It is through a diversity of educational pedagogies that dominant and minor voices are examined. Without subjecting P4C to various critiques, it latches on an ethically problematic hegemonic position.

Discussions about $\mathrm{P} 4 \mathrm{C}$ provide an opportunity to appreciate the changing interpretation of childhood. It keeps children and childhood on the surface of deliberation and identifies the conditions necessary for education to take place. Various education claims provide a dialogic practice hinged on agency to acknowledge or contest other claims, and be recognised as claims 
worthy of equal concern and equally entitled to be in the public sphere. P4C has offered precisely this opportunity to switch and shift to various concerns of children education.

\subsection{Searches and Spaces}

Finally, debates on $\mathrm{P} 4 \mathrm{C}$ open a window for a closer examination of spaces and mechanisms in the public sphere whereby discourses on children and childhood can unfold. As the world witnesses various sources from which children may learn, one may wonder what spaces are hospitable for P4C. As in history, these may be formal sites of deliberation at the global level and, perhaps more importantly, in everyday sites of education. Cultivating contestations in children education can also take place in informal spaces. Indeed, continued discussions of political issues can take place in schools, homes, places of worship and social practices. Examples of these rather meek and incremental contentions are the anti-colonial and anti-dictatorship movements that started with clandestine discussions that, without guaranteed protection of civil liberties, were able to overcome the insecurity and generate counter-discourses of emancipation. $\mathrm{P} 4 \mathrm{C}$ can also take place in playful and localised versions, which may hopefully bridge various discourses about children's issues today.

\section{Conclusion: P4C as a Self-Revising Syllabus}

Much has happened since the establishment of P4C. For instance, the inflation of academic merits, the transformation to digital age and the post-truth era demonstrate the vulnerability of education. Observers now speak of the crisis of education, reflect on what educators could have done differently, and imagine possible ways forward. Philosophy for Children is just one of the many responses to the continued interpretation of education and children. While there are contesting ideas about $\mathrm{P} 4 \mathrm{C}$, what is clear is that it makes a case for the relevance of continued discussions, at the same time also acknowledging the limits of fixation on normative standards. As experiences of childhood and learning are not universal, there is a question of outcomes. What should be the final product of P4C? For Charles Taylor, the best outcome may not be founded on a consensus, but on a system that considers various contexts and is supported by varying background justifications (Taylor, 1999). Following this argument, the differing discourses on P4C may not warrant equality across cultures but each discourse stands a chance of legitimacy based on a fair consideration of the views of all concerned. This situation leaves enough room for contestation while politically viable agreements are reached on what can be done, albeit for different reasons.

This work sees that $\mathrm{P} 4 \mathrm{C}$ has a promising role if it commits fully to the ethos of epistemic humility - that is if it differentiates between building educational reform by welcoming contesting pedagogies as co-equals and transplanting $\mathrm{P} 4 \mathrm{C}$ in cultures deemed inferior. It celebrates various spaces where pedagogical cultures are anchored, be it public squares, Reddit threads, or traditional schools. It takes pedagogical minorities seriously-those that ask questions and scrutinise current practices, even when what is being investigated are the core values of P4C itself. This however must not be confused with the 'anything-goes' principle. As P4C is committed to innovative education, it does not encourage self-flagellation, but rather careful 
scrutiny of questionable educational practices. P4C may be imperfect but it has something to offer. In this regard, $\mathrm{P} 4 \mathrm{C}$ rests on an advantageous, normative position only insofar as it is a way of ensuring that there is inclusivity and that it does not become a tool for a hegemonic enterprise, consciously or not. The consequences of $\mathrm{P} 4 \mathrm{C}$ are indeed ambivalent in character. There is neither purely liberal hegemony nor entirely conservative control. They are shaped by the historical and social forces per given context and system in which they function. What can be inferred therefore are a multiple possibilities for Philosophy for Children. They can further deepen the benefits of teaching philosophy to children or make them suffer the effects of dogmatic learning. In the end, whereas Philosophy for Children claims that it has long term goals, if one does not pursue further philosophical inquiry in the future The tendency is to believe that philosophy is all that a child has learned during childhood. It is within this continuous, long-term perspective that the purpose of questioning the validity of Philosophy for Children becomes justifiable. While this critique can be challenged for being unsympathetic to children, such discourse can serve crucial roles in rethinking the specific curricula educational institutions formulate. As advised by Ndofirepi and Thokozani (2011, p. 139), "Philosophy for Children within the framework of modern theories of democracy, and its emphasis on the educative potential of learner participation, is better positioned to foster active, critical and inquiring school children".

P4C can be understood otherwise. Rights, justice and virtue are just several words that may represent what $\mathrm{P} 4 \mathrm{C}$ has to offer for children to live up to. How children deal with philosophy depends on how they will be developed as thinkers in the future. These examples, therefore, are partial successes suggesting the continued relevance of philosophy as a discipline. ${ }^{2}$ Philosophy is just getting started given that "[h]omo sapiens is still a young species, and potentially the first of many to mull over intellectual problems" (Schellenberg, 2018). It may be unfair to expect much from a discipline that answers the most difficult questions, save the method of doing so. As it faces a new generation of scholars, it is hoped that philosophy as a discipline will continue to flourish, attracting more participants, hopefully children. In line with this, one also ought to consider that there are stages of learning and growing up and that philosophy is not the first thing to start with in educating children. And if philosophy is just on its way, it is not too late to engage younger participants to join the community of philosophers. Philosophy for children is worth its traditional endeavour of trial and error, "mak[ing] progress one person at a time ... even if people successively grapple with much the same questions and answers, with no answers ever designated as the 'right' ones" (Schellenberg, 2018). It is unimaginable that intelligence will cease to exist and as Dietrich (2011:29) is confident to claim, we can be certain that "if points of view still exist, then so will philosophy". That "[p]hilosophy cannot stand still" (Minorov, 2013) implies that P4C has a promising future.

In the end, theories alone do not create a philosopher, just as mere colours do not immediately generate a painting. Content and pedagogy have to be orchestrated well enough to produce a valuable mind. Teaching is most worthwhile when there is a well understood reason to teach,

\footnotetext{
${ }^{2}$ Even though human beings have existed for millions of years already, it does not immediately mean that thinking, let alone critical thinking, is practiced. The pre-agricultural conditions are not conducive to deep thinking and philosophizing because of the imminent threat from nature and the need to satisfy physiological needs first.
} 
and when the most effective means to manage new methods are understood. This sort of understanding is enriched best by teachers who understand the importance of context and the corresponding pragmatic circumstance at hand, in order to invoke the most promising pedagogical results. The students will, as well, know if they have an understanding of philosophy and how to marshal their minds in the deliberation. The challenge of stimulating insightful perception from a generation with speedy access to information is genuine; that is not to say impossible, though. But careless pedagogy may only result in pointless abstractions, rampant in the work done during previous decades.

\section{Funding}

This research was supported by the Russian Science Foundation (grant № 18-18-00236).

\section{References}

Aries, P. (1962). Centuries of Childhood: A Social History of Family Life. New York: Vintage.

Baker, V. L., Baldwin, R. G. \& Makker, S. (2012). Where are they now? Where are They Now? Revisiting Breneman's Study of Liberal Arts Colleges. Liberal Education, 98(3), 48-53.

Bonefield, W. (2014), Critical Theory and the Critique of Political Economy: On Subversion and Negative Reason, London: Bloomsbury.

Burgh, G. \& Thornton, S. (2018) (eds). Growing up with philosophy in Australia: philosophy as cultural discourse. In Philosophical inquiry with children: the development of an inquiring society in Australia (pp. 236-249). Abingdon Oxon: Routledge.

Cassidy, C. (2017) Philosophy with Children: A Rights-Based Approach to Deliberative Participation. International Journal of Children's Rights, 25(2), 320-334.

Chetty, D. (2014). The Elephant in the Room: Picturebooks, Philosophy for Children and Racism. Childhood and Philosophy, 10(19), 11-31

Christiano, T. (2001). Knowledge and power in the justification of democracy. Australian Journal of Philosophy, 79(2): 197-215.

Cohen, E. (2005). Neither Seen Nor Heard: Children's Citizenship in Contemporary Democracies. Citizenship Studies, 9(2), 221-240.

Daniel, M.-F. (1994). Women, Philosophical Community of Inquiry and the Liberation of Self. Thinking, 11(3-4), 63-71.

Darwall, S. L. (2004): Respect and the Second-Person Standpoint. Proceedings and Addresses of the American Philosophical Association, 78(2), 43-59.

Derrida, J. (1994). Spectres of Marx: The State of the Debt, the Work of Mourning, \& the New International. London: Routledge.

Dewey, J. (1966). Democracy and Education. New York: Free Press.

Dietrich, E. (2011). There is No Progress in Philosophy. Essays in Philosophy, 12(2), 9-30. 
Elster, J. (ed) (1998). Deliberative Democracy. Cambridge: Cambridge University Press.

Erricker, C., Erricker, J., Sullivan, D., Ota, C. \& Fletcher, M. (1997). The Education of the Whole Child London: Cassell.

Finkel, N. J., \& Moghaddam, F. M. (2005). The psychology of rights and duties: Empirical contributions and normative commentaries. Washington, DC: American Psychological Association

Hand, M. \& Winstanley, C. (2008). Philosophy in Schools. London: Continuum.

Haynes, J. (2008) Children as Philosopher London: Routledge

Haynes, J. \& Murris, K. (2012). Picturebooks, Pedagogy and Philosophy. New York: Routledge.

James, A. (1993). Childhood Identities: Self and Social Relationships in the Experience of the Child, Edinburgh: Edinburgh University Press.

Juuso, H. (2007). Child, Philosophy and Education: Discussing the intellectual sources of Philosophy for Children. Oulu: Oulu University Press.

Kehily, M. J. (2004). Understanding Childhood: An Introduction to Some Key Themes and Issues. In M. J. Kehily (Ed.) An Introduction to Childhood Studies (pp. 1-22). Maidenhead: Open University Press.

Kizel, A. (2019). Enabling identity as an ethical tension in a community of philosophical inquiry with children and young adults. Global Studies of Childhood, 9(2), 145-155

Kohan, W. (1995). The Origin, Nature, and Aim of Philosophy in Relation to Philosophy for Children, Thinking, 12(2), 25-30.

Kjørholt, A. T. (2007). Childhood as a Symbolic Space: Searching for Authentic Voices on the Era of Globalization. Children's Geographies, 5(1-2), 29-42.

Kuhn, D. (2001). How Do People Know? Psychological Science, 12(1), 1-8.

Letseka, M. (2014). Africanising Philosophy for Children (P4C) in the South African Context. Mediterranean Journal of Social Sciences, 5(9), 348-355.

Levinas, E. (1969/2004). Philosophy and the Idea of Infinity, trans A. Lingis In E. Levinas (Ed), Collected Philosophical Papers (pp. 47-59). The Hague: Martinus Nijhoff.

Lipman, M. (1993), Thinking Children and Education. Dubuque: Kendall / Hunt.

Locke, J. (1960). Two Treatises of Government. Cambridge: Cambridge University.

Lyon, A. (2013). Deliberative Acts: Democracy, Rhetoric, and Rights. University Park: The Pennsylvania State University Press.

Meehan, C. (2007). Teachers Beliefs about Religious Education in the Early Years. In J. Grajczonek \& M. Ryan (Eds), Religious Education in Early Childhood: A Reader (pp.138-157). Brisbane: Lumino Press.

Mills, C. W. (1997). The Racial Contract, New York: Cornell University.

Mironov, V. (2013). On Progress in Philosophy. Metaphilosophy, 44(1-2), 10-14.

Mohr Lone, J. \& Burroughs, M. (2016). Philosophy in Education: Questioning and Dialogue in Schools. Lanham, MD: Rowman and Littlefield 
Nelson, L. (1922). The Socratic Method, In M. Lipman (Ed), Thinking Children and Education (pp. 437-443). Dubuque: Kendall / Hunt.

Nespor, J. (1987). The Role of Beliefs in the Practice of Teaching. Journal of Curriculum Studies, 19(4), 317- 328.

Ndofirepi, A. P. (2011). Philosophy for Children: the Quest for an African perspective. South African Journal of Education, 31, 246-256.

Ndofirepi, A. \& Thokozani, M. (2011). Philosophy for Children in South African Schools: Its Role for Citizens-in-Waiting. South African Journal of Childhood Education, 1(2), 127-142.

Nishiyama, K. (2017). Deliberators, not Future Citizens: Children in Democracy. Journal of Public Deliberation, 13(1), 1-26.

O'Toole, T. (2003). Engaging with Young People's Conceptions of the Political. Children's Geographies, 1(1), 71-90.

Polonko, K. \& Lombardo, L. (2005) Human Dignity and Children: Operationalizing a Human Rights Concept. Global Bioethics 18(1), 17- 35.

Qvortrup, J. (2004). The Waiting Child, Childhood, 11(3): 267-273.

Rainville, H. Y. (2000). Philosophy for Children in Native America: A Post-Colonial Critique. Analytical Thinking, 21(1), 65-77. Retrieved from: http://citeseerx.ist.psu.edu/viewdoc/download?doi=10.1.1.565.1122\&rep=rep1\&type=pdf.

Rivage-Seul, M. (1987). Critical Thought or Domestication? Philosophical Studies in Education: Proceedings-Annual (1987-1988). In F. Estes (ed), Meeting of the Ohio Valley Philosophy of Education Society (pp. 230-246). Terre Haute, Indiana: OVPES.

Schellenberg, J. L. (2018). Why philosophy is taking its time to answer the big questions. AEON, Retrieved from: https://aeon.co/essays/why-philosophy-is-taking-its-time-to-answer-the-bigquestions.

Sowey, M. (2012). Philosophy for Children: A Reflective Approach to Human Rights Education. Right Now Editorial: Children and Youth. Retrieved from http://rightnow.org.au/opinion-3/philosophy-for-children-a-reflective-approach-to-human-rights-education/

Storme, T. \& Vlieghe, J. (2012). The Experience of Childhood and the Learning Society: Allowing the Child to be Philosophical and Philosophy to be Childish. In N. Vansieleghem \& D. Kennedy (Eds), Philosophy for Children in Transition: Problems and Prospects (pp.13-29). Blackwell Publishing Ltd.

Suissa, J. (2008) Philosophy in the Secondary School - a Deweyan Perspective. In M. Hand \& C. Winstanley (Eds) Philosophy in Schools (pp. 132-145). London: Continuum.

Taylor, C. (1999). Conditions of an Unforced Consensus on Human Rights. In J. Bauer \& D. Bell (Eds), The East Asian Challenge for Human Rights (pp. 124-144). New York, Cambridge University Press.

UNESCO (2009). Teaching Philosophy in Asia and the Pacific. United Nations Educational, Scientific and Cultural Organization. Paris: UNESCO. Retrieved from: https://unesdoc.unesco.org/ark:/48223/pf0000185217 
Aireen Grace Andal is a Junior Researcher and graduate student of Political Philosophy at the Department of Philosophy, Ural Federal University named after the first Russian President Boris Yeltsin.

The editorial and publishing process of this publication has been financed by the Ministry of Science and Higher Education from the funds for the dissemination of research (DUN) within the framework of publishing activity, contract no. 711/P-DUN/2019, period of implementation: the years 2019-2020. 